\title{
Risk scores for predicting incident chronic kidney disease among rural Chinese people: a village-based cohort study
}

\author{
Jiangping Wen ${ }^{1 *}$, Jie Hao ${ }^{2}$, Ye Zhang ${ }^{2}$, Kai Cao ${ }^{3}$, Xiaohong Zhang ${ }^{1}$, Jiang $\mathrm{Li}^{4}$, Xinxin $\mathrm{Lu}^{1 *}$ and Ningli Wang ${ }^{2,3^{*}}$
}

\begin{abstract}
Background: Few chronic kidney disease (CKD) risk prediction models have been investigated in low- and middleincome areas worldwide. We developed new risk scores for predicting incident CKD in low- and middle-income rural Chinese populations.

Methods: Data from the Handan Eye Study, which was a village-based cohort study and conducted from 2006 to 2013, were utilized as part of this analysis. The present study utilized data generated from 3266 participants who were $\geq 30$ years of age. Two risk models for predicting incident CKD were derived using two-thirds of the sample cohort (selected randomly) using stepwise logistic regression, and were subsequently validated using data from the final third of the sample cohort. In addition, two simple point systems for incident CKD were generated according to the procedures described in the Framingham Study. CKD was defined as reduced renal function (estimated glomerular filtration rate (eGFR) $<60 \mathrm{~mL} / \mathrm{min} / 1.73 \mathrm{~m}^{2}$ ) or the presence of albuminuria (urinary albumin-to-creatinine ratio (UACR) $\geq 30 \mathrm{mg} / \mathrm{g}$ ).

Results: The Simple Risk Score included waist circumference, systolic blood pressure (SBP), diabetes, sex, and education. The Best-fit Risk Score included urinary albumin-to-creatinine ratio, SBP, C-reactive protein, triglyceride, sex, education, and diabetes. In the validation sample, the areas under the receiver operating curve of the Simple Risk Score and Best-fit Risk Score were 0.717 (95\% Cl, 0.689-0.744) and 0.721 (95\% Cl, 0.693-0.748), respectively; the discrimination difference between the score systems was not significant $(P=0.455)$. The Simple Risk Score had a higher Youden index, sensitivity, and negative predictive value, with an optimal cutoff value of 14 .
\end{abstract}

Conclusions: Our Simple Risk Score for predicting incident CKD in a low- and middle-income rural Chinese population will help identify individuals at risk for developing incident CKD.

Keywords: Risk score, Chronic kidney disease, Rural China

\footnotetext{
*Correspondence: wenjiangping1224@126.com; luxinxin2009@126.com; wningli@vip.163.com

'Department of Laboratory Medicine, Beijing Tongren Hospital, Capital Medical University, No. 1 Dongjiaominxiang, Beijing 100730, Dongcheng District, China

${ }^{2}$ Beijing Tongren Eye Center, Beijing Tongren Hospital, Capital Medical

University, Beijing Ophthalmology and Visual Science Key Laboratory, No. 1

Dongjiaominxiang, Beijing 100730, Dongcheng District, China

Full list of author information is available at the end of the article
}

(c) The Author(s). 2020 Open Access This article is licensed under a Creative Commons Attribution 4.0 International License, which permits use, sharing, adaptation, distribution and reproduction in any medium or format, as long as you give appropriate credit to the original author(s) and the source, provide a link to the Creative Commons licence, and indicate if changes were made. The images or other third party material in this article are included in the article's Creative Commons licence, unless indicated otherwise in a credit line to the material. If material is not included in the article's Creative Commons licence and your intended use is not permitted by statutory regulation or exceeds the permitted use, you will need to obtain permission directly from the copyright holder. To view a copy of this licence, visit http://creativecommons.org/licenses/by/4.0/. The Creative Commons Public Domain Dedication waiver (http://creativecommons.org/publicdomain/zero/1.0/) applies to the data made available in this article, unless otherwise stated in a credit line to the data. 


\section{Background}

Chronic kidney disease (CKD) is strongly associated with an increased risk of developing end-stage renal disease, cardiovascular disease (CVD), and death [1]. Epidemiological studies have shown that the prevalence of CKD varies across countries and regions, including developed and developing areas [1-6]. CKD is highly prevalent in low- and middle-income areas $[2,3,7,8]$. In China, a recent national survey reported that the prevalence of CKD was $10.8 \%$ and the number of patients with CKD was estimated to be about 119.5 million; however, awareness of CKD was only $12.5 \%$ [2]. Therefore, CKD prevention has become a major public health issue in China.

Predicting individual risk is the first step in the primary prevention of CKD. Risk scores that can identify those at higher risk for future CKD have been proposed as prediction and stratification methods $[9,10]$. Several risk scores for predicting incident CKD have been developed and validated in Western populations [11-14]. These risk scores are based on clinical and laboratory information and have been suggested for use as tools to screen individuals considered to be high-risk for developing CKD in developed countries. However, a recent study showed that there is a higher prevalence of earlystage CKD and a lower prevalence of decreased renal function in China compared to the US [4]. Possible explanations for these variations include differences in ethnicities, socioeconomic statuses, risk factors, and genetic susceptibilities to renal disease [4]. Therefore, an ethnoor region-specific risk score for incident CKD was needed. Further, China, as the world's largest developing country, has experienced a rapid increase in the prevalence of diabetes, hypertension, and obesity [2, 15]. To date, several cross-sectional studies have reported the prevalence of CKD and associated risk factors in Chinese populations $[2,8,16]$; however, a tool for predicting the risk of developing CKD in Chinese populations living in low- and middle-income areas had not been developed.

In China, screening for CKD should be a priority in low- and middle-income areas, because early intervention is likely to be effective in reducing the high morbidity and mortality rates resulting from CKD. In this study, we aimed to develop a simple risk score for predicting incident $C K D$ in a population living in a low- and middle-income rural area of China. This CKD scoring system is simple and can be integrated into the rural primary health care system and help screen individuals that may be at risk for CKD.

\section{Methods}

\section{Study population}

We used the data from the Handan Eye Study (HES). Details of the rationale, design, methods and procedures related to this study were provided in our previous reports [17, 18]. The HES was a village-based cohort study to investigate eye diseases and other health-related problems among general rural residents aged $\geq 30$ years old living in Yongnian County (a rural county of Handan City and located about $500 \mathrm{~km}$ south of Beijing). In this area, $80 \%$ of the population is engaged in agricultural production, $98 \%$ are Han people, and the net income per capita is 3468 yuan (approximately 468 USD), which is equivalent to the average income of the residents of China (3587 Yuan, 484 USD) [18]. This study was carried out in accordance with the Helsinki Declaration and approved by the Ethics Committee of Beijing Tongren Hospital (approval number \# TREC2006-22). All subjects provided written informed consent. The right forefinger stamp was considered a signature substitute for illiterate people, which has been approved by the Ethics Committee.

As shown in Fig. 1, 7557 of the 8653 subjects screened were considered eligible for HES. A total of 6830 participants participated in HES from October 2006 to October 2007, and a follow-up survey was carried out from May 2012 to June 2013 [17]. At baseline, 1686 participants declined to provide blood or urine samples, and 886 participants who were diagnosed with CKD were excluded. CKD was defined by reduced renal function (estimated glomerular filtration rate [eGFR] $<60 \mathrm{~mL} / \mathrm{min} /$ $1.73 \mathrm{~m}^{2}$ ) or albuminuria (urinary albumin-to-creatinine ratio [UACR] $\geq 30 \mathrm{mg} / \mathrm{g}$ ) [19]. In follow-up, 992 individuals did not have available eGFR or UACR data.

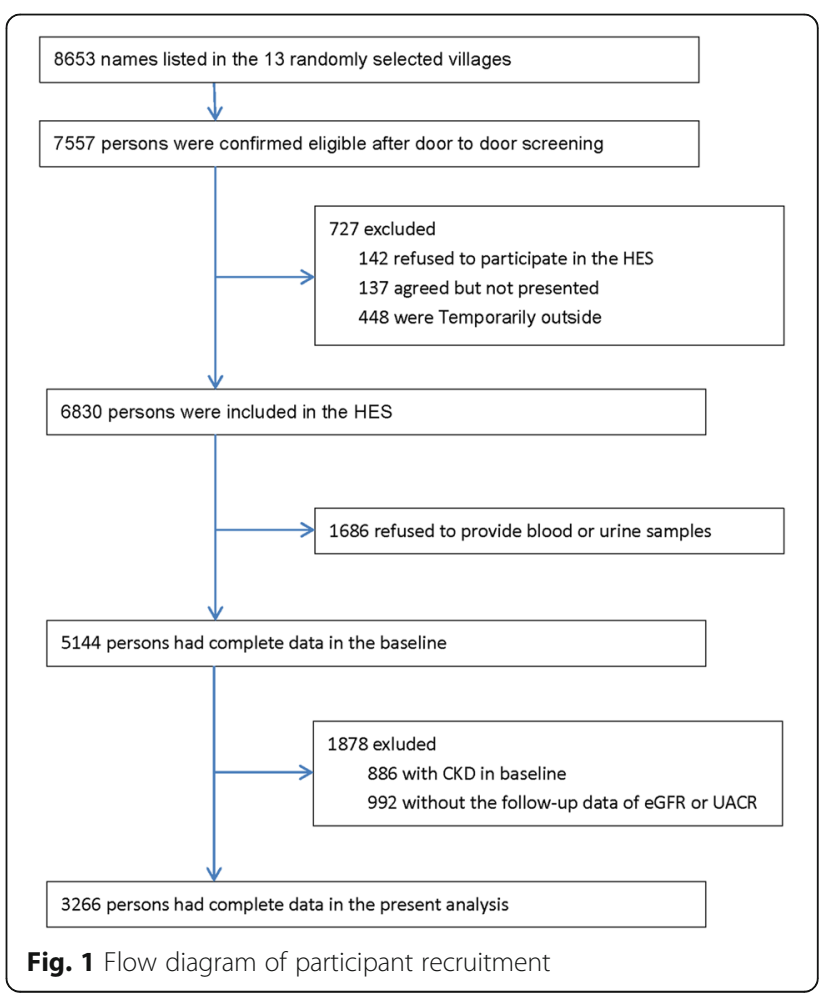


Consequently, 3266 participants were incorporated into the final analysis (Fig. 1).

\section{Data collection}

The survey was carried out in local rural health centers. Interviewers with standard training obtained demographic information through questionnaires, including birth date, sex, ethnicity, occupation, education, smoking, drinking, physical activity, dietary habits and medical history. According to the number of years of education, they were divided into four groups (illiterate for 0 years, primary school for 1-6 years, junior high school for 7-9 years, and senior high school for $\geq 10$ years). Physical activity was divided into three groups, including low exercise (little or no exercise), moderate exercise (walking or bicycling for more than $10 \mathrm{~min}, 1-3$ times a week) and high exercise (leading to rapid breathing for more than $10 \mathrm{~min}$, more than 3 times a week). Smoking and drinking were separated into three groups (never used, current user, and former user). Dietary habits included two categories (fresh fruit and vegetables). Consumption of fresh fruit and vegetables was divided into four frequency levels: $\geq 3$ times per week, 1-2 times per week, 1-3 times per month, and never/very little.

During medical examinations, participants took two blood pressure measurements using a non-invasive automatic HEM-907 blood pressure monitor (OMRON, Kyoto, Japan) after 5 minutes of rest. Systolic blood pressure (SBP) and diastolic blood pressure (DBP) were identified as the average values of two independent measurements. Body mass index (BMI) was calculated by weight $(\mathrm{kg})$ /height $\left(\mathrm{m}^{2}\right)$.

All participants were asked to fast for at least 8 hours before drawing blood, which was taken in the morning in their respective villages. Serum creatinine was determined by the Jaffé kinetic method, fasting blood glucose (FPG) by the hexokinase method and serum lipid by the enzymatic method (Olympus AU27 00, Tokyo, Japan). Urinary albumin and creatinine were measured from fresh morning spot urine samples. Urinary albumin was determined by immunoturbidimetry (Holzheim Diasys Diagnostic Company, Germany). Urinary creatinine was determined by the same method as serum creatinine.

The HES baseline survey was carried out from October 2006 to October 2007, and the follow-up survey was carried out from May 2012 to June 2013. The baseline and follow-up surveys were carried out in local rural health centers, and CKD related data were collected at baseline and follow-up, seperately. CKD related data included demographic information, blood pressures, anthropometric measurements, serum and urine creatinine, and urinary albumin. CKD was defined by reduced renal function or the presence of albuminuria. Reduced renal function was defined by an eGFR $<60 \mathrm{~mL} / \mathrm{min} / 1.73 \mathrm{~m}^{2}$ and albuminuria was defined by a UACR $\geq 30 \mathrm{mg} / \mathrm{g}$. The GFR estimation equation included serum creatinine, age and gender.

\section{Definitions of diabetes, hypertension, and CVD}

Diabetes was defined as: (1) FPG $\geq 7.0 \mathrm{mmol} / \mathrm{L}$, or (2) self-reported diagnosis of diabetes, or (3) the use of antidiabetic medications [20]. Hypertension was defined as: (1) SBP $\geq 140 \mathrm{mmHg}$, or (2) DBP $\geq 90 \mathrm{mmHg}$, or (3) the use of antihypertensive medications [21]. CVD was defined as self-reported coronary heart disease, stroke, peripheral artery disease, or ankle-brachial index $<0.9$ in either leg.

\section{Definition of CKD}

CKD was defined by reduced renal function or the presence of albuminuria [19]. Albuminuria was defined by a UACR $\geq 30 \mathrm{mg} / \mathrm{g}$. Because serum creatinine was measured via the Jaffé kinetic method, the modified Chinese equation was used [22]. Reduced renal function was defined by an eGFR $<60 \mathrm{~mL} / \mathrm{min} / 1.73 \mathrm{~m}^{2}$, calculated as follows:

$\mathrm{eGFR}=175 \times\left(\mathrm{Scr}_{\text {Jaffe }}\right)^{-1.234} \times(\text { Age in years })^{-0.179}(\times 0.79$ for women), where Scr indicates serum creatinine concentration (in $\mathrm{mg} / \mathrm{dL}$ ).

\section{Statistical analysis}

In this study, SPSS v.18.0 software (IBM Corp., Chicago, IL, USA) was used for statistical analysis. The current analysis was limited to 3266 subjects with complete CKD data. The baseline characteristics of the subjects were described according to CKD status at follow-up. The means (standard deviations) or medians (interquartile ranges) were used for continuous variables, and the counts and percentages were used for categorical variables. Unpaired t-test or Mann-Whitney U-test were used to compare the average or median values, and chisquare test was used to analyze the categorical variables.

In this study, two-thirds of the samples were randomly selected as training samples, and the risk factors associated with incident CKD were investigated by forward stepwise logistic regression. CKD definition was a binary outcome with a cutoff of eGFR $<60 \mathrm{~mL} / \mathrm{min} / 1.73 \mathrm{~m}^{2}$ or UACR $\geq 30 \mathrm{mg} / \mathrm{g}$. Based on previous studies, we identified a number of candidate risk factors, including age, sex, blood pressure, BMI, waist circumference (WC), smoking, alcohol consumption, education level, physical activity, diabetes, hypertension and CVD. In final models, only statistically significant risk factors were retained.

According to the methods described by Sullivan and colleagues in the Framingham risk score study [23], we developed a simple scoring system to estimate the risk of CKD. Firstly, continuous variables were classified and 
the reference values of each variable were defined separately. Secondly, the median value of each category was determined and the difference between each category and the reference in regression units was calculated. Thirdly, beta regression coefficients of continuous variables and classified variables are calculated, and the constant reflecting the increase of risk associated with WC or UACR was set. Finally, the score of each predictor was calculated by the product of the corresponding regression coefficients and the difference between the median of each predictor and the relevant reference group. The total scoring range was estimated according to the scoring calculated by each predictor.

After establishing the scoring system, we assessed its diagnostic ability for the remaining one-third of the samples (test samples). The sensitivity and 1-specificity of each cut point was used to plot the receiver operating characteristic curve. The areas under the receiver operating characteristic curve (AUC) were calculated based on the current risk scores. The predictive accuracy of the risk scoring systems can be assessed according to the AUC. We used Horsmer-Lemeshaw test to estimate the calibration characteristics of predictive scores. One of the non-significant $P$ values indicates that there was a good consistency between the observed results and the model-based predictions. The optimal cutoff point of each risk scoring system was that the sum of sensitivity and specificity was the maximum. In addition, sensitivity, specificity, positive and negative predictive values, positive and negative likelihood ratio and Youden index were calculated. A two-sided $P$ value $<0.05$ was considered statistically significant.

\section{Results}

\section{Baseline characteristics}

As shown in Fig. 1, a total of 6830 participants participated in HES. At baseline, 1686 participants declined to provide blood or urine samples, and 886 participants who were diagnosed with CKD were excluded. The current analysis was limited to 3266 participants with complete CKD data. As shown in Table 1, at baseline, the proportion of women was $55.3 \%$, illiterate or primary school education was $64.4 \%$, regular physical activity was $69.3 \%$, and hypertension was $45.6 \%$. Compared to those without incident CKD, the participants who developed CKD were more likely to be women, to have a history of hypertension and diabetes, and to be taking antihypertensive agents; however, they tended to drink and smoke less, consumed fewer fresh fruits, and had lower education levels. They also were older and had higher BMIs, WCs, blood pressures, FPGs, total cholesterol levels, triglyceride levels, UACRs, and C-reactive protein (CRP) levels, but their eGFRs were lower.

\section{CKD incident rates}

Of the 3266 participants who presented without CKD at baseline, 590 (18.1\%) developed CKD during a median of 5.6 years of follow-up. Of these, 565 (95.8\%) participants with CKD were identified by the presence of albuminuria (UACR $\geq 30 \mathrm{mg} / \mathrm{g}$ ) and $38(6.4 \%)$ had reduced renal function $\left(\mathrm{eGFR}<60 \mathrm{~mL} / \mathrm{min} / 1.73 \mathrm{~m}^{2}\right)$.

\section{Risk models for predicting incident CKD}

As shown in Table 2, two risk models for incident CKD were derived in the forward stepwise multivariable logistic regression analysis in the training population. The factors significant in the simple clinical model were sex, WC, SBP, diabetes, and education. The best-fit model included sex, SBP, diabetes, education, triglyceride, UACR, and CRP. The AUCs of the simple and best-fit models were 0.714 (95\% confidence interval [CI], 0.686$0.742)$ and 0.725 (95\% CI, 0.697-0.752) in the training samples, respectively.

\section{Development of risk scores for predicting incident CKD}

As shown in Tables 3 and 4, risk algorithms for the simple clinical model and the best-fit model were converted to risk scores based on the logistic regression coefficients and reference values for each significant risk factor. The Simple Risk Score included WC (4 points), SBP (23 points), sex (11 points), education (- 8 points), and diabetes (16 points) (Table 3$)$. The Best-fit Risk Score included UACR (4 points), SBP (29 points), CRP (2 points), triglyceride (5 points), sex (13 points), education (-10 points), and diabetes (18 points) (Table 4). As shown in Table 5 and Fig. 2, the values indicating the performance of the Simple Risk Score (derived from the simple clinical model) were: $X^{2}=4.89, P=0.769$, AUC $=$ 0.717 (95\% CI, 0.689-0.744), $P<0.001$, and for the Bestfit Risk Score (derived from the best-fit Model) were: $\chi^{2}=2.52, P=0.961$, AUC $=0.721$ (95\% CI, 0.693-0.748), $P<0.001$.

In the validation population, the difference in discrimination (AUC) between the Simple and the Best-fit Risk Score was not significant $(P=0.455)$. Compared with the best fitted risk score, when the optimal cut-off value was 14 , the simple risk score had higher Youden index (0.3563), sensitivity (70.49\%) and negative predictive value (91.3\%). In addition, $66.6 \%$ of the participants had a risk $\leq 20.0,28.9 \%$ had a risk $>20.0 \%$ but $\leq 40.0$, and $4.5 \%$ had a risk $>40 \%$ using the Simple Risk Score system.

\section{Discussion}

\section{Main findings}

Using clinical demographic characteristics and laboratory information, we developed two risk scoring systems to predict the 5-year risk of incident CKD in a rural Chinese population of individuals aged 30 years 
Table 1 Baseline characteristics of participants with and without incidentchronic kidney disease (CKD) at follow-up

\begin{tabular}{|c|c|c|c|c|}
\hline Characteristic & Total $(n=3266)$ & Without incident CKD $(n=2676)$ & With incident CKD $(n=590)$ & $P$ value \\
\hline Age (years) & $50 \pm 10$ & $50 \pm 10$ & $53 \pm 10$ & $<0.001$ \\
\hline Female sex, n (\%) & $1805(55.3)$ & $1392(52.0)$ & $413(70.0)$ & $<0.001$ \\
\hline $\mathrm{BMI}\left(\mathrm{kg} / \mathrm{m}^{2}\right)$ & $24.6 \pm 3.5$ & $24.5 \pm 3.5$ & $25.1 \pm 3.4$ & $<0.001$ \\
\hline Waist circumference $(\mathrm{cm})$ & $87.2 \pm 9.3$ & $86.8 \pm 9.2$ & $89.1 \pm 9.5$ & $<0.001$ \\
\hline SBP $(\mathrm{mmHg})$ & $137.2 \pm 20.7$ & $134.9 \pm 19.5$ & $147.5 \pm 22.7$ & $<0.001$ \\
\hline $\mathrm{DBP}(\mathrm{mmHg})$ & $77.3 \pm 11.7$ & $76.4 \pm 11.2$ & $81.1 \pm 13.0$ & $<0.001$ \\
\hline Total cholesterol (mmol/L) & $4.56 \pm 0.91$ & $4.53 \pm 0.90$ & $4.72 \pm 0.95$ & $<0.001$ \\
\hline HDL-cholesterol (mmol/L) & $1.27 \pm 0.28$ & $1.28 \pm 0.28$ & $1.26 \pm 0.31$ & 0.167 \\
\hline LDL-cholesterol (mmol/L) & $2.68 \pm 0.63$ & $2.65 \pm 0.63$ & $2.80 \pm 0.64$ & $<0.001$ \\
\hline Triglycerides (mmol/L) & $1.24(0.87-1.79)$ & $1.20(0.85-1.73)$ & $1.42(0.98-2.08)$ & $<0.001$ \\
\hline Fasting plasma glucose (mmol/L) & $5.49(5.16-5.89)$ & $5.48(5.14-5.86)$ & $5.58(5.24-6.08)$ & $<0.001$ \\
\hline CRP (mg/L) & $0.80(0.37-2.05)$ & $0.75(0.35-1.88)$ & $1.17(0.49-2.75)$ & $<0.001$ \\
\hline Urea (mmol/L) & $4.78 \pm 1.19$ & $4.77 \pm 1.17$ & $4.82 \pm 1.27$ & 0.340 \\
\hline Creatinine (mmol/L) & $70.9 \pm 9.9$ & $71.1 \pm 9.8$ & $70.2 \pm 10.3$ & 0.081 \\
\hline $\mathrm{eGFR}, \mathrm{ml} / \mathrm{min} / 1.73 \mathrm{~m}^{2}$ & $102.6 \pm 16.1$ & $103.3 \pm 16.3$ & $99.6 \pm 14.8$ & $<0.001$ \\
\hline Albumin-to-creatinine ratio (mg/g) & $6.89(3.42-12.60)$ & $6.60(3.30-12.10)$ & $8.52(4.32-15.33)$ & $<0.001$ \\
\hline Current smoker, n (\%) & $890(27.3)$ & $786(29.4)$ & $104(17.6)$ & $<0.001$ \\
\hline Current drinker, n (\%) & $610(18.7)$ & $543(20.3)$ & $67(11.4)$ & $<0.001$ \\
\hline Regular consumption of fresh fruits, n (\%) & $315(9.6)$ & $280(10.5)$ & $35(5.9)$ & 0.006 \\
\hline Regular consumption of fresh vegetables, n (\%) & $3245(99.4)$ & $2659(99.4)$ & $586(99.3)$ & 0.907 \\
\hline Education, n (\%) & & & & $<0.001$ \\
\hline Illiterate & $398(12.2)$ & $280(10.5)$ & $118(20.0)$ & \\
\hline Primary School & $1704(52.2)$ & $1392(52.0)$ & $312(52.9)$ & \\
\hline Junior high & $1062(32.5)$ & $915(34.2)$ & $147(24.9)$ & \\
\hline Senior high & $102(3.1)$ & $89(3.3)$ & $13(2.2)$ & \\
\hline Physical activity, n (\%) & & & & 0.856 \\
\hline Low & $595(18.2)$ & $483(18.0)$ & $112(19.0)$ & \\
\hline Moderate & $409(12.5)$ & $337(12.6)$ & $72(12.2)$ & \\
\hline High & $2262(69.3)$ & $1856(69.4)$ & $406(68.8)$ & \\
\hline Hypertension, n (\%) & $1488(45.6)$ & $1099(41.1)$ & $389(65.9)$ & $<0.001$ \\
\hline Diabetes, n (\%) & $161(4.9)$ & $88(3.3)$ & $73(12.4)$ & $<0.001$ \\
\hline Cardiovascular disease, n (\%) & $234(7.2)$ & $185(6.9)$ & $49(8.3)$ & 0.235 \\
\hline Use of antihypertensive agents, n (\%) & $600(18.4)$ & $409(15.3)$ & $191(32.4)$ & $<0.001$ \\
\hline Use of lipid-lowering agents, n (\%) & $58(1.8)$ & $45(1.7)$ & $13(2.2)$ & 0.385 \\
\hline Use of anti-diabetic agents, n (\%) & $44(1.3)$ & $23(0.9)$ & $21(3.6)$ & $<0.001$ \\
\hline
\end{tabular}

Data are presented as means \pm standard deviations, medians (interquartile ranges), or numbers (percentages). Chi-square test was used for categorical variables and the unpaired $t$ test or Mann-Whitney $U$ test was used for continuous variables

CKD Chronic kidney disease, BMI Body mass index, SBP Systolic blood pressure, DBP Diastolic blood pressure, HDL-C High density lipoprotein cholesterol, LDL-C Low density lipoprotein cholesterol, CRP C-reactive protein, eGFR Estimated glomerular filtration rate

and older. The Simple Risk Score was as useful as the Best-fit Risk Score for screening individuals at high-risk of developing CKD in a rural Chinese population. The Simple Risk Score is based on five clinical variables (sex, WC, SBP, diabetes, and education) and does not require blood or urine tests. In addition, the clinical variables in the scoring system can be easily obtained from families and health clinics, and it is also simple to use in rural China.

\section{Comparison with other risk scores}

To our knowledge, several useful risk scores for predicting incident CKD have been developed in Western 
Table 2 Stepwise logistic regression analyses of risk factors for incident CKD in the training population

\begin{tabular}{|c|c|c|c|c|}
\hline & Variables & $\beta$-Coefficient & Odd ratios $(95 \% \mathrm{Cl})$ & $\boldsymbol{P}$ value \\
\hline \multirow[t]{6}{*}{ Simple clinical model } & Intercept & -6.168 & & $<0.001$ \\
\hline & Waist circumference & 0.013 & $1.01(1.00-1.03)$ & 0.045 \\
\hline & Sex & 0.686 & $1.99(1.56-2.53)$ & $<0.001$ \\
\hline & Education & -0.532 & $0.59(0.43-0.80)$ & 0.001 \\
\hline & Diabetes & 1.042 & $2.83(1.85-4.33)$ & $<0.001$ \\
\hline & SBP & 0.025 & $1.03(1.02-1.03)$ & $<0.001$ \\
\hline \multirow[t]{8}{*}{ Best-fit model } & Intercept & -5.530 & & \\
\hline & Sex & 0.652 & $1.92(1.50-2.45)$ & $<0.001$ \\
\hline & Education & -0.516 & $0.60(0.44-0.81)$ & 0.001 \\
\hline & Diabetes & 0.923 & $2.52(1.64-3.86)$ & $<0.001$ \\
\hline & SBP & 0.025 & $1.03(1.02-1.03)$ & $<0.001$ \\
\hline & Triglycerides & 0.175 & $1.19(1.07-1.32)$ & 0.001 \\
\hline & CRP & 0.027 & $1.03(1.01-1.05)$ & 0.011 \\
\hline & Albumin-to-creatinine ratio & 0.017 & $1.02(1.00-1.03)$ & 0.030 \\
\hline
\end{tabular}

CKD Chronic kidney disease, SBP Systolic blood pressure, CRP C-reactive protein, $\mathrm{Cl}$ Confidence interval

populations in developed areas, such as the United States and Europe $[11,13,14]$. In those studies, the prediction models for incident CKD showed that age, sex, diabetes, hypertension, CVD, eGFR, and albuminuria were associated with a risk of incident CKD with AUC values ranging from 0.70 to 0.88 .
Asians have the highest prevalence of CKD worldwide [3] and the risk factors for incident CKD are different in Asian populations in developed versus low- and middleincome areas. In developed areas, such as in Japan [24], researchers found that older age, proteinuria, hematuria, higher SBP, taking antihypertensive and/or anti-diabetic

Table 3 Algorithm for estimating the risk of CKD using total point values in the simple model

\begin{tabular}{|c|c|c|c|c|}
\hline Risk factor & Reference value $\left(W_{i j}\right)$ & $\beta_{i}$ & $\beta_{\mathbf{i}}\left(W_{\mathbf{i j}}-W_{\mathbf{i R E F}}\right)$ & Point $_{\mathbf{i j}}=\beta_{\mathbf{i}}\left(W_{\mathbf{i j}}-W_{\mathbf{i R E F}}\right) / B^{a}$ \\
\hline Waist circumference, men/women $(\mathrm{cm})$ & & 0.013 & & \\
\hline$<80 / 75$ & $77.0 / 72.0\left(\mathrm{~W}_{1 \mathrm{REF}}\right)$ & & 0 & 0 \\
\hline $80-84.9 / 75-79.9$ & $82.5 / 77.5$ & & 0.072 & 1 \\
\hline $85-89.9 / 80-84.9$ & $87.5 / 82.5$ & & 0.137 & 2 \\
\hline $90-94.9 / 85-89.9$ & $92.5 / 87.5$ & & 0.202 & 3 \\
\hline$\geq 95 / 90$ & 99.0/95.0 & & 0.286 & 4 \\
\hline SBP $(\mathrm{mmHg})$ & & 0.025 & & \\
\hline$<120$ & $110\left(W_{2 R E F}\right)$ & & 0 & 0 \\
\hline $120-139$ & 130 & & 0.500 & 8 \\
\hline $140-159$ & 150 & & 1.000 & 15 \\
\hline$>160$ & 170 & & 1.500 & 23 \\
\hline Sex & & 0.686 & & \\
\hline Men & $1\left(W_{3 R E F}\right)$ & & 0 & 0 \\
\hline Women & 2 & & 0.686 & 11 \\
\hline Education & & -0.532 & & \\
\hline Illiterate & $1\left(\mathrm{~W}_{4 \mathrm{REF}}\right)$ & & 0 & 0 \\
\hline Primary School and above & 2 & & -0.532 & -8 \\
\hline Diabetes & & 1.042 & & \\
\hline NO & $O\left(W_{5 R E F}\right)$ & & 0 & 0 \\
\hline YES & 1 & & 1.042 & 16 \\
\hline
\end{tabular}

${ }_{\mathrm{B}} \mathrm{B}=5^{*} 0.013=0.065$; CKD: Chronic kidney disease; SBP: systolic blood pressure 
Table 4 Algorithm for estimating the risk of CKD using total point values in the best-fit model

\begin{tabular}{|c|c|c|c|c|}
\hline Risk factor & Reference value $\left(\mathrm{W}_{\mathrm{ij}}\right)$ & $\beta_{i}$ & $\beta_{\mathbf{i}}\left(W_{\mathbf{i j}}-W_{\mathbf{i R E F}}\right)$ & Point $_{\mathbf{i j}}=\beta_{\mathbf{i}}\left(W_{\mathbf{i j}}-W_{\mathbf{i R E F}}\right) / B^{a}$ \\
\hline Urinary Albumin-to-creatinine ratio & & 0.017 & & \\
\hline$<5.0$ & $2.68\left(\mathrm{~W}_{1 \mathrm{REF}}\right)$ & & 0 & 0 \\
\hline $5.0-10.0$ & 7.16 & & 0.076 & 1 \\
\hline$>10.0$ & 15.71 & & 0.222 & 4 \\
\hline SBP $(\mathrm{mmHg})$ & & 0.025 & & \\
\hline$<120$ & $110\left(W_{2 R E F}\right)$ & & 0 & 0 \\
\hline $120-139$ & 130 & & 0.500 & 10 \\
\hline $140-159$ & 150 & & 1.000 & 20 \\
\hline$>160$ & 170 & & 1.500 & 29 \\
\hline CRP & & 0.027 & & \\
\hline$<1.0$ & $0.40\left(W_{3 R E F}\right)$ & & 0 & 0 \\
\hline $1-3$ & 1.73 & & 0.036 & 1 \\
\hline$>3.0$ & 4.66 & & 0.115 & 2 \\
\hline Triglycerides & & 0.175 & & \\
\hline$<1.0$ & $0.77\left(\mathrm{~W}_{4 \mathrm{REF}}\right)$ & & 0 & 0 \\
\hline $1.0-1.7$ & 1.30 & & 0.093 & 2 \\
\hline$>1.7$ & 2.26 & & 0.261 & 5 \\
\hline Sex & & 0.652 & & \\
\hline Men & $1\left(\mathrm{~W}_{5 \mathrm{REF}}\right)$ & & 0 & 0 \\
\hline Women & 2 & & 0.6520 & 13 \\
\hline Education & & -0.516 & & \\
\hline Illiterate & $1\left(\mathrm{~W}_{6 \mathrm{REF}}\right)$ & & 0 & 0 \\
\hline Primary School or more & 2 & & -0.5160 & -10 \\
\hline Diabetes & & 0.923 & & \\
\hline NO & $O\left(W_{\text {TREF }}\right)$ & & 0 & 0 \\
\hline YES & 1 & & 0.9230 & 18 \\
\hline
\end{tabular}

${ }_{\mathrm{B}}^{\mathrm{B}}=3^{*} 0.017=0.051 ; C K D$ Chronic kidney disease, SBP Systolic blood pressure, CRP C-reactive protein

medications, and current smoking were associated with and increased risk of CKD and higher eGFR and daily alcohol intake were associated with a lower risk. The Cstatistics for the risk estimation equations for CKD at 10 years were $>0.8$. In Taiwan [25], Chien and colleagues established a clinical prediction risk model based on age, BMI, DBP, and history of type 2 diabetes and stroke in a cohort study that had poor discriminatory power (c-statistic 0.67) and short-term follow-up (median 2.2 years). In a recent study conducted in low- to middle-income

Table 5 Performance of our risk scores in the prediction of incident CKD in the validation population

\begin{tabular}{|c|c|c|c|c|c|c|c|c|c|c|c|}
\hline Scores & $\begin{array}{l}\text { Risk factors in the } \\
\text { score }\end{array}$ & AUC & $\begin{array}{l}\text { Optimal } \\
\text { cutoff value }\end{array}$ & Sensitivity & Specificity & $+\mathrm{LR}$ & $-L R$ & $+P V$ & $-P V$ & $\begin{array}{l}\text { Youden } \\
\text { index }\end{array}$ & $\begin{array}{l}\text { Hosmer } \\
\text { and } \\
\text { Lemeshow } \\
\text { Test }\end{array}$ \\
\hline $\begin{array}{l}\text { Simple } \\
\text { risk } \\
\text { score }\end{array}$ & $\begin{array}{l}\text { Sex, education, } \\
\text { WC, diabetes, } \\
\text { SBP. }\end{array}$ & $\begin{array}{l}0.717 \\
(0.689-0.744)\end{array}$ & $>14$ & $\begin{array}{l}70.49 \\
(63.30-77.00)\end{array}$ & $\begin{array}{l}65.14 \\
(61.90-68.30)\end{array}$ & $\begin{array}{l}2.02 \\
(1.80-2.30)\end{array}$ & $\begin{array}{l}0.45 \\
(0.40-0.60)\end{array}$ & $\begin{array}{l}29.8 \\
(25.5-34.4)\end{array}$ & $\begin{array}{l}91.3 \\
(88.8-93.4)\end{array}$ & 0.3563 & 0.769 \\
\hline $\begin{array}{l}\text { Best-fit } \\
\text { risk } \\
\text { score }\end{array}$ & $\begin{array}{l}\text { Sex, education, } \\
\text { diabetes, SBP, } \\
\text { triglycerides, } \\
\text { CRP, UACR. }\end{array}$ & $\begin{array}{l}0.721 \\
(0.693-0.748)\end{array}$ & $>24$ & $\begin{array}{l}56.83 \\
(49.30-64.10)\end{array}$ & $\begin{array}{l}76.61 \\
(73.70-79.40)\end{array}$ & $\begin{array}{l}2.43 \\
(2.00-2.90)\end{array}$ & $\begin{array}{l}0.56 \\
(0.50-0.70)\end{array}$ & $\begin{array}{l}33.8 \\
(28.5-39.3)\end{array}$ & $\begin{array}{l}89.4 \\
(87.0-91.5)\end{array}$ & 0.3344 & 0.961 \\
\hline
\end{tabular}




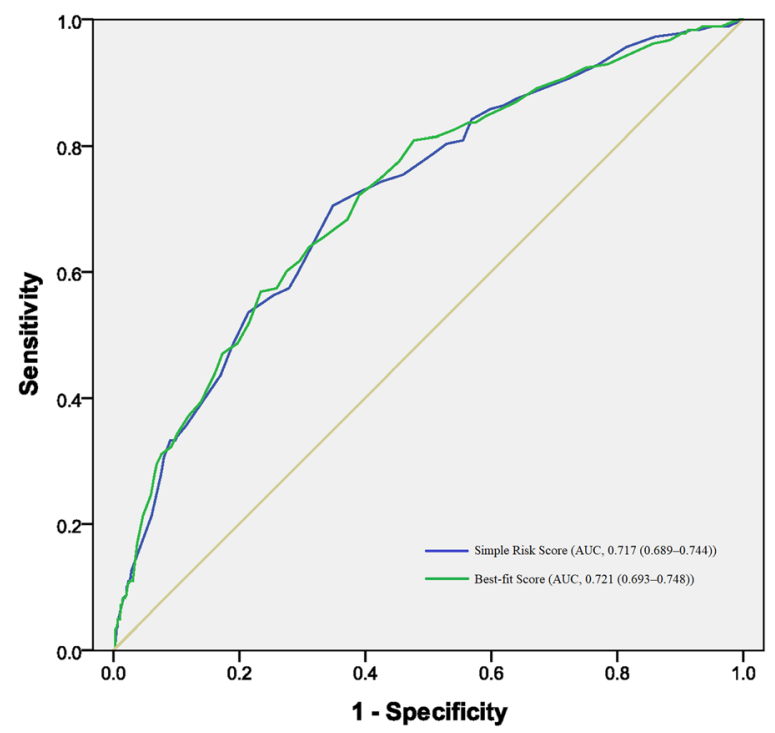

Fig. 2 Receiver operating characteristic curves for the two new risk scores applied to the validation population

areas in Thailand [26], age, sex, SBP, diabetes, and WC were significant predictors for their clinical score, while age, sex, SBP, diabetes, and eGFR were predictors in the combined clinical and laboratory model. Both risk scores had a high degree of accuracy and discriminatory power in the Thai population (AUC 0.72-0.79). However, those two simple clinical risk scores that were derived from populations in Taiwan and Thailand performed poorly when tested in our cohort (AUC 0.615 and 0.621, respectively).

In our study, we developed two risk scores based on a general population living in a low- and middle-income rural area in Northern China. Compared with most previous studies, age was not highly associated with the risk of incident CKD in the present study. In our scoring system, SBP, diabetes, and sex were more important contributors to the overall score. Education was also an important clinical predictor of CKD, although it was not included in other scoring models developed in Western and other Asian populations. There are several explanations for the differences between our study and previous studies. First, we defined CKD as either reduced renal function or by the presence of albuminuria. In our study population, $95.8 \%$ were identified by the presence of albuminuria and $6.4 \%$ were identified by reduced renal function (eGFR $<60 \mathrm{~mL} / \mathrm{min} / 1.73 \mathrm{~m}^{2}$ ). Second, China is the world's largest developing country with a rapidly increasing prevalence of diabetes, hypertension, and obesity $[2,15,27]$. The prevalence rates of hypertension, diabetes, and obesity in our rural population were 45.6, 4.9 , and $13.9 \%$, respectively; however, the percentages of use of antihypertensive and anti-diabetic medications were only 40.3 and $27.3 \%$, respectively. Third, $12.2 \%$ of our participants were illiterate and $52.2 \%$ were educated to the primary school level; thus, in our study, education levels were negatively associated with a risk of CKD. Finally, compared with men, women had higher BMIs and SBPs but lower education levels and were less physically active.

\section{Strengths and limitations}

To the best of our knowledge, this is the first study to develop simple risk scores for predicting incident CKD in a population living in a low- and middle-income rural area of China. Further, this study was a village-based cohort study, with a detailed assessment of risk factors including measures of baseline renal function and albuminuria. However, there were also several limitations to this study. First, a total of 6830 participants participated in the village-based cohort study from 2006 to 2013; however, only 3266 participants were included in our final analysis, as 3564 participants were excluded for various reasons. Therefore, there may be selection bias. Additionally, compared with previous studies [24-26], this study is relatively small. Second, external validation has not been carried out because there are no data available from other similar studies in China. Third, a family history of kidney disease may be associated with CKD, but questions to identify this information were not addressed in our questionnaires. Fourth, the discriminatory capacity of our Simple Risk Score was moderate (the AUC was 0.717) and somewhat lower than that of other risk scores developed in other populations. Finally, participants with acute renal injury was not ruled out due to the lack of creatinine data for the most recent week at the time of the survey. Moreover, the present scoring system is based on the data of HES from 2006 to 2013, so we must carefully apply these results to the current management of CKD high-risk population.

\section{Conclusions}

In this cohort study, we developed our Simple Risk Score for predicting incident CKD based upon age, sex, SBP, diabetes, and WC. In China, screening for CKD should be a priority in low- and middle-income areas, because early intervention is likely to be effective in reducing the high morbidity and mortality rates resulting from CKD. This simple CKD scoring system can be integrated into the rural primary health care system and help to screen and identify high-risk individuals of incident CKD. This will be particularly beneficial for women with hypertension, overweight, and those with low education levels in rural areas. It is anticipated that this scoring system will improve CKD prevention and 
provide necessary information for the implementation of intervention strategies among rural populations in China.

\section{Abbreviations}

CKD: Chronic kidney disease; eGFR: Estimated glomerular filtration rate; UACR: Urinary albumin-to-creatinine ratio; Cl: Confidence interval; CVD: Cardiovascular disease; HES: Handan eye study; SBP: Systolic blood pressure; DBP: Diastolic blood pressure; BMI: Body mass index; WC: Waist circumference; FPG: Fasting plasma glucose; AUC: Area under the receiver operating characteristic curve; CRP: C-reactive protein; ROC: Receiver operating characteristic curve

\section{Acknowledgments}

We would like to thank all the study participants and the members of the Handan Eye Study group.

\section{Authors' contributions}

JW: Concept, funding acquisition, analysis, and manuscript first draft. JH: Investigation, analysis, and project administration. YZ: Methodology, investigation, data curation. KC: Database management, data curation, and analysis. XZ: data curation, analysis, and manuscript writing. JL: data curation, analysis, and manuscript writing. XL: Concept, analysis, and manuscript review \& editing. NW: Concept, funding acquisition, and manuscript review \& editing. The authors read and approved the final manuscript.

\section{Funding}

This work was supported by the National Basic Research Program of China (973 Program), the Ministry of Science and Technology of China (Grant 2007CB512201), and the Foundation of the Beijing Tongren Hospital (Grant 2005). The funders had no role in the design of the study and collection, analysis, and interpretation of data and in writing the manuscript.

\section{Availability of data and materials}

The datasets used and analysed during the current study are available from the corresponding author on reasonable request.

\section{Ethics approval and consent to participate}

This study was conducted in accordance with the Helsinki Declaration and approved by the Ethics Committee of Beijing Tongren Hospital (approval number \# TREC2006-22). Written informed consent was obtained from all subjects. The right forefinger stamp was considered a signature substitute for illiterate people, which has been approved by the Ethics Committee.

\section{Consent for publication}

Not applicable.

\section{Competing interests}

The authors declare that they have no competing interests.

\section{Author details}

'Department of Laboratory Medicine, Beijing Tongren Hospital, Capital Medical University, No. 1 Dongjiaominxiang, Beijing 100730, Dongcheng District, China. ${ }^{2}$ Beijing Tongren Eye Center, Beijing Tongren Hospital, Capital Medical University, Beijing Ophthalmology and Visual Science Key Laboratory, No. 1 Dongijiaominxiang, Beijing 100730, Dongcheng District, China. ${ }^{3}$ Beijing Institute of Ophthalmology, No. 1 Dongjiaominxiang, Beijing 100730, Dongcheng District, China. ${ }^{4}$ Department of Laboratory Medicine, China-Japan Friendship Hospital, No. 2 Yinghuayuan East Street, Beijing 100029, Chaoyang District, China.

Received: 1 March 2019 Accepted: 29 March 2020

\section{Published online: 06 April 2020}

\section{References}

1. Romagnani P, Remuzzi G, Glassock R, Levin A, Jager KJ, Tonelli M, et al. Chronic kidney disease. Nat Rev Dis Primers. 2017;3:17088.

2. Zhang L, Wang F, Wang L, Wang W, Liu B, Liu J, et al. Prevalence of chronic kidney disease in China: a cross-sectional survey. Lancet. 2012;379(9818): 815-22.
3. Stanifer JW, Muiru A, Jafar TH, Patel UD. Chronic kidney disease in low- and middle-income countries. Nephrol Dial Transplant. 2016;31(6):868-74.

4. Wang $F$, He K, Wang J, Zhao MH, Li Y, Zhang L, et al. Prevalence and risk factors for CKD: a comparison between the adult populations in China and the United States. Kidney Int Rep. 2018;3(5):1135-43.

5. Anand S, Zheng Y, Montez-Rath ME, Wei WJ, Perico N, Carminati S, et al. Do attributes of persons with chronic kidney disease differ in low-income and middle-income countries compared with high-income countries? Evidence from population-based data in six countries. BMJ Glob Health. 2017;2(4): e000453.

6. George C, Mogueo A, Okpechi I, Echouffo-Tcheugui JB, Kengne AP. Chronic kidney disease in low-income to middle-income countries: the case for increased screening. BMJ Glob Health. 2017;2(2):e000256.

7. Nugent RA, Fathima SF, Feigl AB, Chyung D. The burden of chronic kidney disease on developing nations: a 21st century challenge in global health. Nephron Clin Pract. 2011;118(3):c269-77.

8. Jiang L, Liang Y, Qiu B, Wang F, Duan X, Yang X, et al. Prevalence of chronic kidney disease in a rural Chinese adult population: the Handan eye study. Nephron Clin Pract. 2010;114(4):C295-302.

9. Taal MW, Brenner BM. Predicting initiation and progression of chronic kidney disease: developing renal risk scores. Kidney Int. 2006;70(10): 1694-705.

10. James MT, Hemmelgarn BR, Tonelli M. Early recognition and prevention of chronic kidney disease. Lancet. 2010;375(9722):1296-309.

11. Kshirsagar AV, Bang H, Bomback AS, Vupputuri S, Shoham DA, Kern LM, et al. A simple algorithm to predict incident kidney disease. Arch Intern Med. 2008;168(22):2466-73.

12. Hippisley-Cox J, Coupland C. Predicting the risk of chronic kidney disease in men and women in England and Wales: prospective derivation and externa validation of the QKidney scores. BMC Fam Pract. 2010;11:49.

13. Halbesma N, Jansen DF, Heymans MW, Stolk RP, de Jong PE, Gansevoort RT, et al. Development and validation of a general population renal risk score. Clin J Am Soc Nephrol. 2011;6(7):1731-8.

14. O'Seaghdha CM, Lyass A, Massaro JM, Meigs JB, Coresh J, D'Agostino RB Sr, et al. A risk score for chronic kidney disease in the general population. Am J Med. 2012;125(3):270-7.

15. Xu Y, Wang L, He J, Bi Y, Li M, Wang T, et al. Prevalence and control of diabetes in Chinese adults. JAMA. 2013:310(9):948-59.

16. Lin B, Shao L, Luo Q, Ou-yang L, Zhou F, Du B, et al. Prevalence of chronic kidney disease and its association with metabolic diseases: a cross-sectional survey in Zhejiang province, eastern China. BMC Nephrol. 2014;15:36.

17. Liang YB, Friedman DS, Wong TY, Wang FH, Duan XR, Yang XH, et al. Rationale, design, methodology, and baseline data of a population-based study in rural China: the Handan eye study. Ophthalmic Epidemiol. 2009; 16(2):115-27.

18. Wen J, Liang Y, Wang F, Sun L, Guo Y, Duan X, et al. Association of Creactive protein and metabolic syndrome in a rural Chinese population. Clin Biochem. 2009;42(10-11):976-83.

19. Inker LA, Astor BC, Fox CH, Isakova $T$, Lash JP, Peralta CA, et al. KDOQI US commentary on the $2012 \mathrm{KDIGO}$ clinical practice guideline for the evaluation and management of CKD. Am J Kidney Dis. 2014 63(5):713-35.

20. American DA. 2. Classification and diagnosis of diabetes: standards of medical Care in Diabetes-2019. Diabetes Care. 2019;42(Suppl 1):S13-28.

21. Chobanian AV, Bakris GL, Black HR, Cushman WC, Green LA, Izzo JL Jr, et al. The seventh report of the joint National Committee on prevention, detection, evaluation, and treatment of high blood pressure: the JNC 7 report. JAMA. 2003;289(19):2560-72.

22. Ma YC, Zuo L, Chen JH, Luo Q, Yu XQ, Li Y, et al. Modified glomerular filtration rate estimating equation for Chinese patients with chronic kidney disease. J Am Soc Nephrol. 2006;17(10):2937-44.

23. Sullivan LM, Massaro JM, D'Agostino RB Sr. Presentation of multivariate data for clinical use: the Framingham study risk score functions. Stat Med. 2004; 23(10):1631-60.

24. Umesawa M, Sairenchi T, Haruyama Y, Nagao M, Yamagishi K, Irie F, et al. Validity of a risk prediction equation for CKD after 10 years of follow-up in a Japanese population: the Ibaraki prefectural health study. Am J Kidney Dis. 2018:71(6):842-50

25. Chien KL, Lin HJ, Lee BC, Hsu HC, Lee YT, Chen MF. A prediction model for the risk of incident chronic kidney disease. Am J Med. 2010; 123(9):836-46 e2. 
26. Saranburut K, Vathesatogkit P, Thongmung N, Chittamma A, Vanavanan S, Tangstheanphan T, et al. Risk scores to predict decreased glomerular filtration rate at 10 years in an Asian general population. BMC Nephrol. 2017:18(1):240

27. Hu D, Fu P, Xie J, Chen CS, Yu D, Whelton PK, et al. Increasing prevalence and low awareness, treatment and control of diabetes mellitus among Chinese adults: the InterASIA study. Diabetes Res Clin Pract. 2008;81(2):250-7.

\section{Publisher's Note}

Springer Nature remains neutral with regard to jurisdictional claims in published maps and institutional affiliations.

Ready to submit your research? Choose BMC and benefit from:

- fast, convenient online submission

- thorough peer review by experienced researchers in your field

- rapid publication on acceptance

- support for research data, including large and complex data types

- gold Open Access which fosters wider collaboration and increased citations

- maximum visibility for your research: over $100 \mathrm{M}$ website views per year

At $\mathrm{BMC}$, research is always in progress.

Learn more biomedcentral.com/submissions 